\title{
PENGUJIAN PERFORMA REAKTOR DOWNDRAFT BIOMASSA KOTORAN SAPI
}

\author{
Muhammad Ridwan dan Noviyanti Nugraha \\ Jurusan Teknik Mesin, Fakultas Teknologi Industri, ITENAS Bandung \\ e-mail: muhrid@gmail.com
}

\begin{abstract}
Biomass power plants are electricity generators with alternative energy that utilize organic materials, in this case cow dung. The cow dung is then processed to produce syngas. Syngas is used as fuel to turn turbines. In previous studies, a cow manure gasification reactor was designed and manufactured. This reactor is part of a biomass power plant system $(P L T B m)$ which is made separately. The power output target of this PLTBm is $370 \mathrm{~kW}$. The purpose of this study was to examine the performance of the downdraft reactor of cow dung biomass, namely discharge, temperature, and analyze the gas content released by the reactor so that the power that can be generated by the reactor can be obtained. The test results obtained a combustion chamber temperature of $580^{\circ} \mathrm{C}$ and a discharge of $0.285 \mathrm{~m} 3 / \mathrm{s}$. The composition of the output gas is acetylene $58.16 \%$, hexane $27.66 \%$, butane $6.38 \%$, and methane $7.8 \%$. From the calculation results, the power generated by the reactor is $342 \mathrm{~kW}$.
\end{abstract}

Keywords: Experiment, Performance, Reactor, PLTBm, Cow Dung.

\section{PENDAHULUAN}

Gasifikasi adalah suatu proses konversi senyawa yang mengandung karbon untuk mengubah material baik cair maupun padat menjadi bahan bakar gas mampu bakar $\left(\mathrm{CO}, \mathrm{H}_{2}, \mathrm{CO}_{2}, \mathrm{CH}_{4}\right.$ dan $\left.\mathrm{H}_{2} \mathrm{O}\right)$ melalui proses pembakaran dengan suplai udara terbatas yaitu antara $20 \%$ hingga $40 \%$ udara stoikiometri.

Reaktor tempat terjadinya proses gasifikasi disebut gasifier. Selama proses gasifikasi akan terbentuk daerah proses menurut distribusi temperatur dalam reaktor. Daerah-daerah tersebut adalah pengeringan, pirolisis, pembakaran, dan gasifikasi. Masing-masing daerah terjadi pada rentang suhu antara $25^{\circ} \mathrm{C}$ hingga $150^{\circ} \mathrm{C}, 150^{\circ} \mathrm{C}$ hingga $600^{\circ} \mathrm{C}, 600^{\circ} \mathrm{C}$ hingga $900^{\circ} \mathrm{C}$, dan $600 \mathrm{~K}$ hingga $900 \mathrm{~K}$. Gas hasil dari proses gasifikasi disebut syngas [1].

Pembangkit listrik tenaga biomassa merupakan pembangkit listrik dengan energi alternatif yang memanfaatkan bahan organik, dalam hal ini kotoran sapi. Kotoran sapi ini kemudian diolah sehingga dapat manghasilkan syngas. Syngas inilah yang pada akhirnya dapat digunakan sebagai bahan bakar untuk memutar turbin. Seberapa besar daya yang dapat dibangkitkan sangat bergantung dari performa alat tersebut. Komposisi syngas bervariasi tergantung dengan bahan baku biomassa, namun rata-rata dapat menghasilkan syngas dengan kadar $\mathrm{H}_{2}$ sebesar $18-20 \%$, CO sebesar $18-20 \%$, $\mathrm{CH}_{4}$ sebesar $2-3 \%, \mathrm{CO}_{2}$ sebesar $12 \%, \mathrm{H}_{2} \mathrm{O}$ sebesar $2,5 \%$ dan sisanya $\mathrm{N}_{2}$, dengan nilai kalor gas sekitar $4,7-5 \mathrm{MJ} / \mathrm{m}^{3}[2]$.

Pembakaran bahan bakar gas (syngas) lebih mudah dalam pengontrolan laju atau temperatur pembakaran dibanding pembakaran bahan bakar padat. Disamping itu, hasil pembakaran bahan bakar gas lebih bersih. Namun, untuk menghasilkan syngas dari gasifikasi, teknologi gasifikasi masih harus dikembangkan karena efisiensi tertinggi proses gasifikasi masih disekitar 65\% [3].

Banyak parameter yang mempengaruhi efisiensi gasifikasi dan sangat tergantung dari jenis bahan bakar dan tipe gasifier yang dipakai. Pemanasan awal udara gasifikasi merupakan parameter penting yang berpengaruh terhadap efisiensi gasifikasi. Pemanasan tersebut dapat membantu mengurangi kandungan moisture bahan bakar. Semakin kecil persentase moisture dalam bahan bakar padat, nilai kalor syngas semakin besar. Namun, pemanasan awal udara gasifikasi harus dicari nilai optimumnya sehingga tidak menimbulkan permasalahan lagi yaitu terbentuknya tar [3]. Karena udara adalah agen gasifying, temperatur reaktor tergantung pada laju aliran udara dan laju umpan biomassa [4].

Gasifikasi yang selama ini sering dikenal adalah gasifikasi dengan umpan batubara dan limbah pertanian, akan tetapi gasifikasi dengan umpan limbah peternakan khususnya biomassa 
kotoran sapi masih jarang dilakukan, padahal kotoran sapi memiliki potensi yang besar untuk dikembangkan sebagai bahan bakar gasifikasi.

Kotoran sapi yang telah melalui proses pengeringan akan diperoleh mass moisture content (wt\%) sebesar 10\%. Sedangkan kotoran sapi yang belum dikeringkan rata-rata memiliki mass moisture content sebesar $78.4 \%$.

Tipe reaktor yang digunakan adalah tipe downdraft. Pada tipe ini sumber panas terletak di bawah bahan bakar, aliran udara bergerak ke zona gasifikasi dibagian bawah yang menyebabkan asap pirolisa yang dihasilkan melewati zona gasifikasi yang panas. Hal ini membuat tar yang terkandung dalam asap terbakar, sehingga gas yang dihasilkan oleh reaktor ini lebih bersih [5].

Keuntungan reaktor tipe ini adalah reaktor ini dapat digunakan untuk operasi gasifikasi yang berkesinambungan dengan menambahkan bahan bakar melalui bagian atas reaktor. Namun untuk operasi yang berkesinambungan dibutuhkan sistem pengeluaran abu yang baik, agar bahan bakar bisa terus ditambahkan kedalam reaktor [5].

Pada penelitian sebelumnya telah dirancang serta dibuat reaktor gasifikasi kotoran sapi. Reaktor ini adalah bagian dari sistem PLTBm (Pembangkit Listrik Tenaga Biomassa) yang dibuat terpisah. Target keluaran dari PLTBm ini adalah $370 \mathrm{~kW}$, seperti yang diperlihatkan pada Gambar 1 . Untuk itu diperlukan pengujian performa dari reaktor tersebut. Maka tujuan dari penelitian ini adalah menguji kinerja dari reaktor downdraft biomassa kotoran sapi.

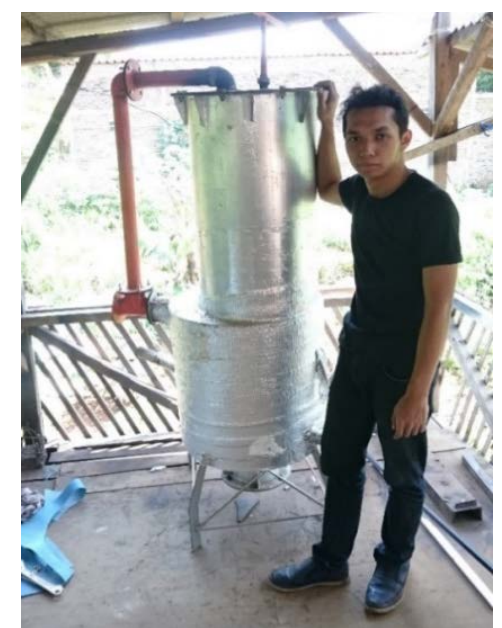

Gambar 1. Reaktor downdraft

\section{METODOLOGI}

Skema beserta komponen reaktor downdraft yang akan diuji diperlihatkan pada Gambar 2.

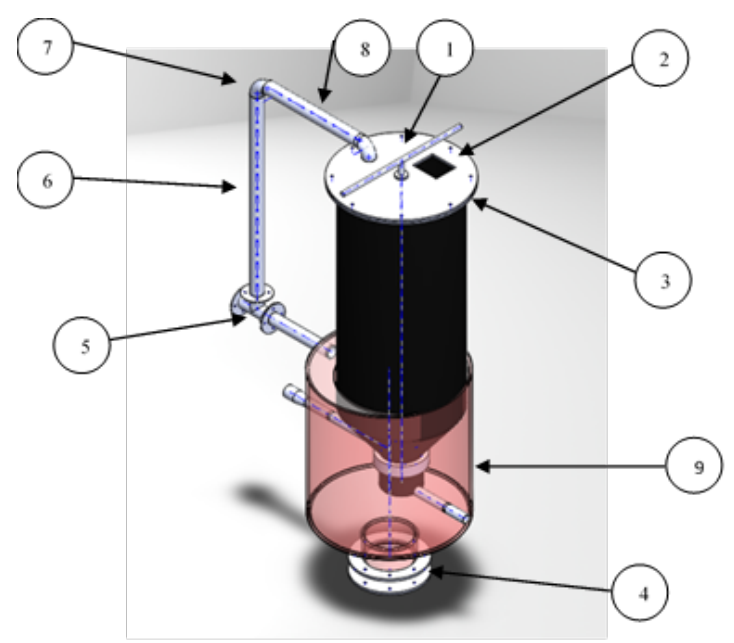

Komponen-komponen Reaktor downdraft

1. Tiang paddle.

2. Lubang untuk memasukkan bahan baku.

3. Tutup.

4. Saringan ash grate.

5. Sambungan pipa T.

6. Pipa panjang $720 \mathrm{~mm}$.

7. Belokan 2 in.

8. Pipa panjang $582 \mathrm{~mm}$.

9. Gasifier

Gambar 2. Komponen reaktor downdraft 
Reaktor downdraft gasifikasi biomassa ini terdiri dari beberapa komponen utama yaitu: Gasifier (tungku gasifikasi), berfungsi sebagai komponen utama sebagai tungku tempat berlangsungnya proses gasifikasi, dimana biomassa dibakar dengan temperatur tinggi sehingga menghasilkan sintetik gas (syngas). Gasifier terbuat dari pipa baja, plat baja dan piringan (plate) baja. Reaktor gasifier terdiri dari throat atau leher reaktor yang terbuat dari pipa baja dan hearth atau tungku pembakaran dari plat baja yang di-bending menyerupai kerucut.

Syngas outlet (tempat pengeluaran syngas) berfungsi sebagai saluran pengeluaran syngas yang dihasilkan gasifier. Bahan yang digunakan untuk syngas outlet ini adalah pipa ST-40 dengan diameter 3 inchi dan panjang $10 \mathrm{~cm}$.

Air nozzle (nozzle udara) berfungsi sebagai sumber udara pada proses gasifikasi dan sebagai pengatur arah aliran syngas. Air nozzle (nosel udara) ini terbuat dari material pipa ST-40 dengan diameter $8 \mathrm{~mm}$ yang terdiri dari 8 buah nozzle dimana 4 nozzle terpasang horizontal dan 4 nozzle lainnya terpasang miring $45^{0}$ ke bawah.

Ash grate berfungsi sebagai tempat penampung abu dari sisa pembakaran biomassa. Ash grate terbuat dari plat baja ST-40 dengan ketebalan $2 \mathrm{~mm}$ yang di-roll menyerupai tabung dan di-bending menyerupai kerucut. Pada saringan ash grate terdapat banyak lubang saringan agar memudahkan pada saat penyaringan bekas pembakaran yang berupa abu ke dalam ash grate.

Hopper (corong) berfungsi untuk tempat memasukkan biomassa ke dalam reaktor. Hopper (corong) terbuat dari plat baja ST-40 dengan ketebalan $2 \mathrm{~mm}$ yang di-roll membentuk tabung dengan diameter $45 \mathrm{~cm}$ dan tinggi $100 \mathrm{~cm}$.

Pipa dengan panjang $582 \mathrm{~mm}$ digunakan untuk aliran sisa pembakaran dari atas hopper yang disambungkan ke belokan 2 in. Pipa dengan panjang 720 mm digunakan untuk aliran sisa pembakaran dari atas hopper yang disambungkan ke belokan 2 in dan diteruskan ke syngas output. Belokan 2 in yang digunakan sebanyak 2 buah, 1 buah dipasangkan diatas tutup flens hopper dan yang lain disambungkan pada sambungan pipa $582 \mathrm{~mm}$ dan pipa $720 \mathrm{~mm}$. Sambungan T digunakan untuk membagi aliran dari atas hopper dan dari output syngas. Pipa-pipa ini juga dimaksudkan untuk mengatasi adanya syngas ke atas.

Tiang paddle yang diletakkan didalam reaktor, digunakan untuk memasangkan screw pendorong bahan bakar ke ruang pembakaran.

\section{Skema Pengujian}

Skema pengujian reaktor dapat dilihat dari Gambar 3. parameter yang diamati dari reaktor antara lain temperatur ruang bakar, kecepatan udara masuk kedalam reaktor, debit gas keluar reaktor, temperatur gas keluar reaktor, dan kandungan gas keluar reaktor.

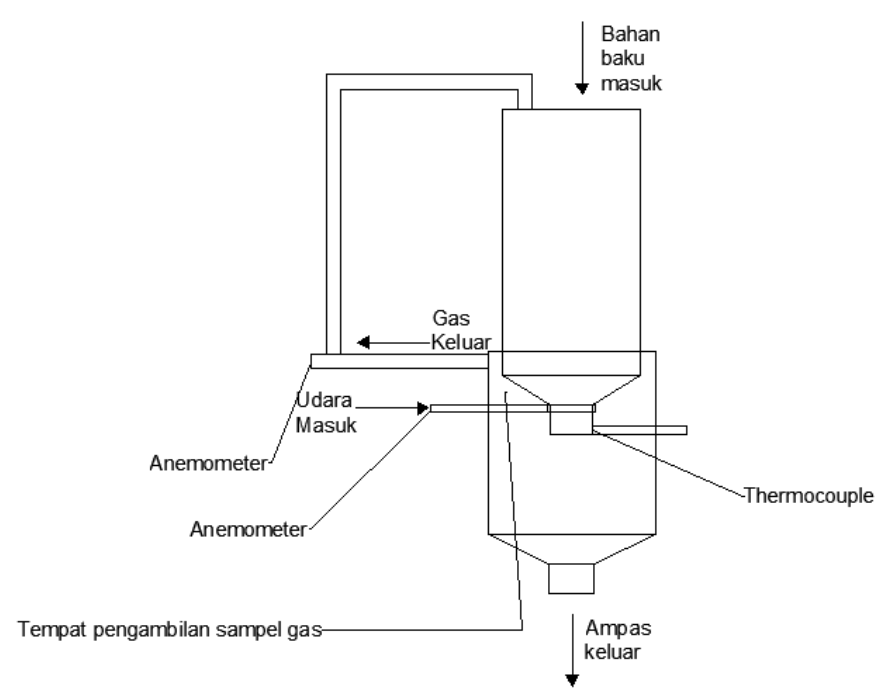

Gambar 3. Skema pengujian reaktor 
Hasil gas yang keluar dari reaktor ditampung ke dalam wadah untuk kemudian dimasukkan ke dalam gas chromatography. Untuk mengukur debit yang keluar dilakukan dengan anemometer, akan diperoleh laju aliran gas yang keluar. Setelah itu akan dikalikan dengan luas penampang pipa, maka diperoleh debit dari gas yang keluar.

\section{Prosedur Pengujian}

1. Memasukkan kotoran sapi ke dalam reaktor.

2. Membakar kotoran sapi dengan gas burner melalui jalur inisiasi.

3. Menyalakan blower dengan bukaan paling kecil.

4. Setelah kotoran sapi menyala di dalam, kemudian menutup jalur inisiasi dengan thermocouple.

5. Menunggu reaktor hingga panasnya mencapai lebih dari $500^{\circ} \mathrm{C}$ sambil memutar tuas secara perlahan.

6. Setelah temperatur reaktor diatas $500^{\circ} \mathrm{C}$, kemudian membuka bukaan blower pada posisi setengah.

7. Mengukur temperatur ruang pembakaran dengan thermocouple.

8. Mengukur laju aliran gas yang keluar dengan anemometer.

9. Mengukur laju aliran yang masuk dengan anemometer.

10. Mengulangi langkah 7 sampai 9 dengan bukaan full sambil terus memutar tuas secara perlahan.

11. Mengambil sampel gas yang keluar dari reaktor kedalam suatu wadah, kemudian menganalisa dengan alat gas chromatography.

12. Mematikan reaktor dengan mematikan blower.

\section{ANALISIS}

Data hasil pengujian yang diperoleh diperlihatkan pada Tabel 1.

Tabel 1. Data hasil pengujian reaktor

\begin{tabular}{ccccc}
\hline $\begin{array}{c}\text { Bukaan } \\
\text { blower }\end{array}$ & $\begin{array}{c}\text { Aliran udara } \\
\text { masuk (m/s) }\end{array}$ & $\begin{array}{c}\text { Aliran syngas } \\
\text { keluar }(\mathbf{m} / \mathbf{s})\end{array}$ & $\begin{array}{c}\text { Temperatur } \\
\text { ruang bakar }\left({ }^{\circ} \mathbf{C}\right)\end{array}$ & $\begin{array}{c}\text { Temperatur syngas } \\
\text { keluar }\left({ }^{\circ} \mathbf{C}\right)\end{array}$ \\
\hline $\begin{array}{c}\text { setengah } \\
\text { full }\end{array}$ & 7.9 & 0.8 & 520 & 135 \\
\hline
\end{tabular}

Hasil gas yang keluar dari reaktor diuji menggunakan gas chromatography, untuk mengetahui kandungannya. Data hasil pengujian diperlihatkan pada Tabel 2.

Tabel 2. Data hasil gas chromatography, LHV, dan densitas gas yang terkandung

\begin{tabular}{cccc}
\hline Nama zat & Area \% & LHV $\left(\mathbf{M J} / \mathbf{m}^{3}\right)$ & Densitas $\mathbf{( k g / \mathbf { m } ^ { 3 } )}$ \\
\hline Udara & 98,59 & - & - \\
Acetaldehyde & 0,82 & 53,9 & 1,092 \\
2-Hexanone & 0,39 & 160,9 & 3,79 \\
2,3-Butanedione & 0,09 & 111 & 2,485 \\
2-Methylfuran & 0,11 & 33,9 & 0,668 \\
\hline
\end{tabular}
dihasilkan.

Perhitungan dilakukan untuk mendapatkan debit gas yang keluar, LHV syngas serta daya yang

\section{Debit Gas yang Keluar}

Untuk menghitung debit gas yang keluar dapat menggunakan persamaan berikut:

$d=2,5$ inchi $=0,0635 \mathrm{~m}$ 
$Q=v \cdot \pi \cdot\left(\frac{d}{2}\right)^{2}=0,9 \frac{m}{s} \cdot \pi \cdot\left(\frac{0,0635 m}{2}\right)^{2}=0,285 \frac{m^{3}}{s}$

\section{LHV Syngas}

Untuk menghitung LHV dari Syngas maka digunakan persamaan berikut, dengan melihat pada hasil gas chromatography pada Tabel 2, sehingga:

$$
\begin{aligned}
L H V_{\text {syngas }} & =X . L H V_{\text {acetylene }}+X . L H V_{\text {hexane }}+X . L H V_{\text {butane }}+X . L H V_{\text {methane }} \\
L H V_{\text {syngas }} & =0,82 \% \cdot 53,9 \frac{M J}{m^{3}}+0,39 \% .160,9 \frac{M J}{m^{3}}+0,09 \% .111 \frac{M J}{m^{3}}+0,11 \% .33,9 \frac{M J}{m^{3}} \\
& =1.2 \frac{M J}{m^{3}}
\end{aligned}
$$

\section{Daya Gas}

Untuk menghitung daya gas menggunakan persamaan berikut:

$$
P_{\text {syngas }}=L H V_{\text {syngas. }} Q=1,2 \frac{M J}{m^{3}} \cdot 0,285 \frac{\mathrm{m}^{3}}{\mathrm{~s}}=0,342 \mathrm{MW}=342 \mathrm{~kW}
$$

Dari pengujian yang dilaksanakan dapat diperoleh analisa sebagai berikut:

1. Reaktor gasifikasi memiliki spesifikasi yang harus dipenuhi yaitu daya keluaran gas sebesar 370 $\mathrm{kW}$, pada data hasil pengujian menunjukkan bahwa reaktor hanya dapat mengeluarkan daya keluaran gas sebesar $342 \mathrm{~kW}$.

2. Dikarenakan reaktor yang diuji tidak berada dalam suatu sistem PLTBm (Pembangkit Listrik Tenaga Biomassa) melainkan berdiri sendiri, mengakibatkan sampel gas yang keluar tercampur dengan udara.

3. Jika dari data yang diperoleh diasumsikan dimana kondisi reaktor berada dalam suatu sistem. Sehingga udara dipisahkan dari sampel dan menyisakan syngas murni. Untuk itu akan diperoleh LHV dan debit yang berbeda sebagai berikut:

Total syngas $=\%$ area acetylene $+\%$ area hexane $+\%$ area butane $+\%$ area methane

Total syngas $=0,82 \%+0,39 \%+0,09 \%+0,11 \%=1,41 \%$

Untuk LHV,

$$
\begin{aligned}
L H V_{\text {syngas }}= & \frac{0,82}{1,41} \times 100 \% .53,9 \frac{M J}{m^{3}}+\frac{0,39}{1,41} \times 100 \% .160,9 \frac{M J}{m^{3}}+\frac{0,09}{1,41} \times 100 \% .111 \frac{M J}{m^{3}}+ \\
& \frac{0,11}{1,41} \times 100 \% .33,9 \frac{M J}{m^{3}}
\end{aligned}
$$

$L H V_{\text {syngas }}=58,16 \% .53,9 \frac{M J}{m^{3}}+27,66 \% .160,9 \frac{M J}{m^{3}}+6,38 \% .111 \frac{M J}{m^{3}}+7,8 \% .33,9 \frac{M J}{m^{3}}$

$L H V_{\text {syngas }}=85,57 \frac{M J}{m^{3}}$

Untuk Debit,

$Q=0,285 \frac{m^{3}}{s} \times 1,41 \%=0,004 \frac{m^{3}}{s}$

Maka berdasarkan persamaan (3) daya dari gas sebagai berikut, 
$P_{\text {syngas }}=L H V_{\text {syngas }} \cdot Q=85,57 \frac{M J}{m^{3}} \cdot 0,004 \frac{m^{3}}{s}=0,3423 M W=342,3 \mathrm{~kW}$

Dapat dilihat bahwa hasil perhitungan murni syngas menghasilkan LHV yang lebih tinggi.

4. Jika dibutuhkan LHV dalam satuan basis massa, maka masing-masing gas dibagi dengan densitasnya yang diperoleh dari Tabel 2. Perhitungannya sebagai berikut.

$$
\begin{aligned}
& L H V_{\text {syngas }}=\frac{X . L H V_{\text {acetylene }}}{\rho_{\text {acetylene }}}+\frac{X \cdot L H V_{\text {hexane }}}{\rho_{\text {hexane }}}+\frac{X \cdot L H V_{\text {butane }}}{\rho_{\text {butane }}}+\frac{X \cdot L H V_{\text {methane }}}{\rho_{\text {methane }}} \\
& L H V_{\text {syngas }}=\frac{58,16 \% \cdot 53,9 \frac{M J}{\mathrm{~m}^{3}}}{1,092 \frac{\mathrm{kg}}{\mathrm{m}^{3}}}+\frac{27,66 \% \cdot 160,9 \frac{\mathrm{MJ}}{\mathrm{m}^{3}}}{3,79 \frac{\mathrm{kg}}{\mathrm{m}^{3}}}+\frac{6,38 \% \cdot 111 \frac{\mathrm{MJ}}{\mathrm{m}^{3}}}{2,485 \frac{\mathrm{kg}}{\mathrm{m}^{3}}}+\frac{7,8 \% .33,9 \frac{\mathrm{MJ}}{\mathrm{m}^{3}}}{0,668 \frac{\mathrm{kg}}{\mathrm{m}^{3}}} \\
& L H V_{\text {syngas }}=47,11 \frac{\mathrm{MJ}}{\mathrm{kg}}
\end{aligned}
$$

\section{SIMPULAN}

1. Debit dari gas yang keluar reaktor adalah sebesar $0,285 \mathrm{~m}^{3} / \mathrm{s}$.

2. Temperatur dari ruang bakar adalah $580{ }^{\circ} \mathrm{C}$ pada bukaan blower maksimal.

3. Adapun komposisi syngas yang dihasilkan adalah:

\begin{tabular}{lrrrr}
\hline Kondisi Syngas & Acetylene & \multicolumn{1}{c}{ Hexane } & \multicolumn{1}{c}{ Butane } & Methane \\
\hline Syngas tercampur udara & $0,82 \%$ & $0,39 \%$ & $0,09 \%$ & $0,11 \%$ \\
\hline Syngas murni & $58,16 \%$ & $27,66 \%$ & $6,38 \%$ & $7,8 \%$ \\
\hline
\end{tabular}

\section{DAFTAR PUSTAKA}

[1] Technology of Biomass Gasification :

http://cgpl.iisc.ernet.in/site/Portals/0/Technologies/GasificationTechnology.pdf diunduh pada April 2017

[2] Muhammad Ridwan, Indradjaja, Faqih Azizuddin dan Stefan Arichta. (2016). Perancangan Reaktor Gasifikasi Downdraft dan Cyclone Separator Pilot Plant Pembangkit Listrik Gasifikasi Biomassa Kapasitas 100 kW. Prosiding Seminar Nasional Tahunan Teknik Mesin XV (SNTTM $\mathrm{XV})$.

[3] Anis,Samsudin, Karnowo, Wahyudi, Sri Mulyo Bondan Respati. (2010). Studi Eksperimen Gasifikasi Sekam Padi pada Updraft Circulating Fluidized Bed Gasifier. Semarang : Jurusan Teknik Mesin Fakultas Teknik Universitas Negeri Semarang

[4] Sadaka, Samy. (2006). Gasification. Nevada: Department of Agricultural and Biosystem Engineering Lowa State University.

[5] Susanto, H. (2005). Pengujian PLTD-Gasifikasi Sekam 100 kW di Haurgeulis, Indramayu. Laporan singkat Pengoperasian PLTD-G sekam di Haurgeulis. 